\title{
Sustentabilidad E Historia Oral: Huellas En El Tiempo. Conceptos Generadores De Nuevo Conocimiento Para La Acción Ciudadana En El Siglo XXI
}

\author{
Gabriela Scartascini Spadaro, Dra. \\ Vilma Zoraida Rodríguez Melchor, Mtra. \\ María Guadalupe Talavera Curiel, Mtra. \\ Universidad de Guadalajara, México
}

doi: 10.19044/esj.2017.v13n26p374 URL:http://dx.doi.org/10.19044/esj.2017.v13n26p374

\begin{abstract}
For several decades, sustainability has been positioned as a paradigmatic concept in relation to the present and the future of our planet. It is a transverse discursive axis in front of countless issues that lead our daily life while trying to preserve, protect or recover it. In recent years, it has surpassed the field of ecology since it has been adopted by different fields that have established specific meanings. Its constant application has been reflected in areas as diverse as environment, tourism, economy, international politics, corporate affairs, education, and even gastronomy.

As for Oral History, since Allan Nevins to date, its credibility and validity were strengthened and valued. In many parts of the world, the twentieth century regained its national, regional and local history through the testimonies of witnesses and protagonists of events that someone, perhaps, had wanted to keep in oblivion. Currently, new issues and problems arise to be considered from the perspective of Oral History, as a valuable resource for the recovery of perspectives, angles, and scope of information, in those same areas that are covered by the need to incorporate into the sustainability in its discourse.

The objective of this proposal is to expose the historical evolution of both the sustainability notion and Oral History as concepts that have passed through the twentieth century and have been constituted as generators of new knowledge articulated with the action of citizens committed to their cultural and natural heritage, history and identity.
\end{abstract}

Keywords: Oral History, Sustainability, Social Transitions 


\section{Resumen}

Desde hace varias décadas, la sustentabilidad se ha posicionado como un concepto paradigmático en relación con el presente y el futuro de nuestro planeta. Es un eje discursivo transversal frente a incontables temas que lideran nuestra vida cotidiana, ya sea porque se plantee la necesidad de preservarla, protegerla o procurar su recuperación. En los últimos años, ha sobrepasado el ámbito de la ecología y ha sido apropiada por diferentes campos que han establecido significaciones específicas. Su constante aplicación se ha visto reflejada en ámbitos tan diversos como medio ambiente, turismo, economía, política internacional, asuntos corporativos, educación y gastronomía.

En cuanto a la Historia Oral, desde aquellos tiempos de Allan Nevins a la fecha, su credibilidad y validez se afianzó y valorizó. En numerosas partes del mundo, el siglo XX recuperó su historia nacional, regional y local a través de los testimonios de testigos y protagonistas de sucesos que alguien, tal vez, hubiera querido guardar en el olvido. En el presente, nuevos temas y problemáticas surgen para ser analizados desde la mirada de la Historia Oral, como recurso valioso para la recuperación de perspectivas, ángulos y alcances de la información, en esos mismos ámbitos que son recorridos por la necesidad de incorporar a la sustentabilidad en su discurso.

El objetivo de esta propuesta es exponer la evolución histórica de los conceptos sustentabilidad e Historia Oral, puesto que se han constituido en generadores de nuevos conocimientos articulados con la acción de ciudadanos comprometidos con su patrimonio cultural y natural, historia e identidad.

Palabras clave: Historia Oral, Sustentabilidad, Transiciones sociales

\section{Introduction}

"Well, we just got him in time!" Allan Nevins, The Gateway to History

Edgar Morin sitúa al hombre actual en un periodo llamado Era Planetaria, el cual inicia en el siglo XIX de nuestra era a partir de las revoluciones tecnológicas, industriales y de imperialismos y se ha desarrollado entre crisis, guerras e incertidumbre. En una evolución no mecánica ni lineal ni determinista sino policausal, la Historia es narrada desde el presente definido desde una complejidad que genera desvíos, rupturas, innovaciones y crisis que producen transiciones en los procesos así como en la valoración y conceptualización de esos rasgos históricos coyunturales en cuanto a su dominancia, emergencia, epigonalidad o cristalización. Morin enfatiza en el hecho de que "ningún factor puede considerarse permanentemente estable, 
constante (...)" ya que los procesos históricos son dinámicos y debemos "pensar nuestro presente, los movimientos de nuestro mundo presente y trabajar con la incertidumbre y no la linealidad" $(2011,22)$

$\mathrm{Si}$ las crisis y las transiciones forman parte natural de los procesos históricos, entonces, las voces dentro de ellas serán las encargadas de exponer la complejidad coyuntural y, si es policausal y no lineal, entonces se requerirán espacios que suenen, organicen y construyan los vértices y aristas de las conceptualizaciones y decisiones coyunturales.

Una mirada unívoca, derivada de los Think Tank, el Estado omnipotente o los organismos internacionales dirigidos por grupos de poder, esfuman la complejidad de los procesos y las posibles transiciones que pueden surgir cuando los procesos históricos son valorados desde perspectivas cuyas variables se articulan de manera independiente.

Conceptos como Sustentabilidad e Historia Oral avalan la noción de transiciones policausales que permiten, desde su evolución a lo largo del último siglo, tomar posiciones que reflexionan y se posicionan desde diversos ángulos de análisis, tanto teóricos como en la praxis. En ambos casos, se proponen fijar una huella que supere las unilateralidades y las decisiones que se centren, solamente, en el presente inmediato.

La sustentabilidad deberá ser el concepto global que articule las variables económica, social y medioambiental.

El crecimiento económico se ha visto desdibujado por la idea economicista de "desarrollo", la cual señala fortaleza en los países a partir de datos macroeconómicos. Pero es bien sabido que desarrollo no es crecimiento ya que este último se asienta en espacios concretos $\mathrm{y}$, a partir de estrategias económicas, genera prosperidad que se ve reflejada en áreas de la salud, vivienda, servicios básicos, educación y empleo para los ciudadanos que habitan el conjunto del territorio. La generación de resiliencia es una consecuencia del crecimiento.

Tomando como referencia a uno de los Objetivos del Desarrollo Sustentable establecidos por la Organización de las Naciones Unidas (ONU) en 2015, las ciudades y comunidades también se enfrentan a problemas de diversa índole generados por la exclusión no solo económica sino social.

De acuerdo con la ONU: "Muchas ciudades son también más vulnerables al cambio climático y a los desastres naturales debido a su elevada concentración de personas y su ubicación, por lo que reforzar la resiliencia urbana es crucial para evitar pérdidas humanas, sociales y económicas" (2015: 2).

Las ciudades dejarán de ser marginales cuando se haga partícipe, a todos los sectores que la habitan, de la inclusión que por derecho humano les corresponde; en ese sentido la explotación racional de los recursos generará 
el equilibrio medioambiental que sostenga el futuro posible en una sustentable era planetaria.

El núcleo de esta reflexión se centra en dos pioneros de los temas que se investigan: Allan Nevins, para la Historia Oral y Juan Luis Cifuentes Lemus, en relación con la sustentabilidad. Sus biografías profundizan en aspectos y situaciones vitales que los establecen, de manera referencial, con conceptos que buscan soluciones para un futuro de ciudadanos sustentables y activos en la defensa de sus vidas.

\section{ALLAN NEVINS (1890-1971): pionero de la Historia Oral}

Su pasión por la Historia data de la infancia en la granja de Illinois, con la biblioteca familiar durante los días lluviosos que daban descanso al trabajo cotidiano.

En 1938, escribe The Gateway to History. En el prefacio, resalta la necesidad de prevalecer la gestación de una Historia viva y con energía que conste de publicaciones escritas para la multitud y no para algunos pocos letrados, así como una organización sistemática que busque obtener, de los testimonios y documentos personales de la gente viva, una completa grabación de su participación en la vida social, política, económica y cultural de los últimos sesenta años "periodo en el cual Estados Unidos se ha construido en la más rica y poderosa nación que el mundo jamás haya visto" (Nevins, 1938: iv)

Destaca su interés en afirmar que la historia es la creadora de las naciones y su inspiradora y que la tradición común se construye a partir de la narración de la historia particular de cada nación. Por ello, para brindarles a los pueblos un nuevo sentido de futuro, se necesita, en primera instancia, al historiador que les dé un nuevo sentido de su pasado y que ayude a recuperar los testimonios orales de los informantes clave del pasado reciente, los cuales deben provenir de los numerosos sectores que participan en el devenir histórico de cada sociedad.

Más adelante, destaca que en el siglo XIX el centro de atención se halla en la evolución del Estado y las políticas y que, en el siglo XX, la Historia basada en la sociedad es la que cobra centralidad y que ese nuevo ángulo de visión surge a partir de la Primera Guerra Mundial, la cual detonó en una ampliación de las articulaciones de la Historia ya que se halla interconectada con el espíritu de su época, tal como la literatura y, también, con todas las Ciencias Sociales

La historia escrita en el futuro deberá ser, necesariamente, ecléctica en el mejor sentido. Porque la verdad completa es la única $y$ verdadera realidad, la Historia como un todo, requiere de las estadísticas, Sociología, Economía, Psicología y Geografía para presentar un completo y exacto cuadro del pasado (pág. 17) 
Con el crecimiento y densidad poblacional así como el avance de la ciencia y la tecnología, se genera la necesidad de hablar de la nueva complejidad social en otros términos: "Se espera que el historiador moderno sepa tratar con los múltiples aspectos de una complejidad cada vez más rica" (pág. 301), así como una actitud crítica y la búsqueda en exactos detalles que superen las propias impresiones personales. Por ello, una nueva historia se requiere para el siglo $\mathrm{XX}$ :

Para la Historia, nuestro entendimiento de los tiempos pasados es más que hechos e ideas; está ligado al espíritu también. Y nuestra comprensión del espíritu de eras pasadas nos es dado no solamente a través de inscripciones, manuscritos y libros sino, en gran medida, por la transmisión de las personas de la época. Una fuerza espiritual corre de generación en generación, de padre a hijo, de maestro a maestro. (pág. 117)

Con el objetivo de una Historia Oral inclusiva, trabajó durante años en la elaboración de una publicación que, finalmente, logró ser editada en 1949 con el nombre de American Heritage.

En American Heritage de diciembre de 1954, se menciona el lanzamiento del material a ser publicado del Proyecto de Historia Oral de la Universidad de Columbia, ideado en 1948 y puesto en marcha por Allan Nevins, quien también se menciona como Director de la revista. Se destaca el hecho de que se recuperarán las memorias de gente que no es conocida por el público en general pero que han formado parte importante de la historia de la economía, la políticas y los procesos sociales, aun en el detrás de escena.

Cabe destacar que esta propuesta inicial de Allan Nevins continúa editándose al día de hoy y American Heritage puede ser consultada, en su totalidad, en internet.

A su vez, Allan Nevins ha dejado testimonio de su historia de vida en entrevistas de historia oral realizadas por Frank Ernest Hill, que se encuentran en la biblioteca de la Universidad de Columbia, en el área de Historia Oral. Los textos mecanografiados datan de 1963, pero fueron dados a conocer con posterioridad a la muerte de Nevins, tal como fue su deseo. (Hill, 1974)

En ellos, relata su vida cotidiana en el rancho de Illinois y su contacto cercano con la naturaleza. Su historia de vida, enlazada a los animales y las tareas rurales y la constante valoración del sentido de pertenencia hacia su granja.

Habla de su formación intelectual que se fue desarrollando en ideas liberales, demócratas, y la asidua participación a clubes de diálogo sobre leyes, literatura, actualidad, medicina y religión.

En el ejercicio de preparación para una vida dedicada a la Historia Oral, Nevins menciona que su trabajo en el periodismo lo llevó al descubrimiento 
de trabajar con la combinación de recursos, en cuanto a documentos históricos, como pueden ser materiales hemerográficos, cartas y diarios personales que fortalecieron sus reportajes.

Respecto de los dos instrumentos de enriquecimiento para la Historia-que le faltaba a Estados Unidos-, sugerida por Nevins en 1938 (una revista y la recolección de testimonios), se abocó a la realización de una revista: "Puse todo mi esfuerzo en generar una buena revista popular de Historia" (Hill, 1974: 170)

Sin embargo, y en tiempos previos a la segunda guerra mundial, los grandes historiadores de la "American Historical Association" dudaron de este proyecto y no se pudo concretar. En respuesta a esa decisión, Nevins crea la "Society of American Historians" que funcionó como base para la edición de la revista American Heritage y, sumado a esto, se dedica a la fundación de la Oficina de Historia Oral en la Universidad de Columbia. Inicia la labor junto a Dean Albertson entrevistando a gente de Nueva York: "Iniciamos con papel, pluma y lápiz, nada más". Desde el inicio, trabajaron en la búsqueda de solvencia económica para transcriptores y material. Pasaron por el "wire recorder" hasta llegar al "tape recorder" que fue la solución, hasta el día de hoy en el cual se reconoce al Programa de Historia Oral de la Universidad de Columbia como un pionero en este campo de las Ciencias Sociales

La Universidad de Columbia fue una valiosa gestora del desarrollo de la Historia Oral en el continente americano, aun cuando con el tiempo los países latinoamericanos fueron más empáticos con la historia oral europea (Meyer, 1989: 140).

Tal vez la evolución de la historia oral en nuestra parte del continente se identifica más con aquella ejercida por europeos (italianos e ingleses), los cuales, encauzan claramente el rescate de historias de vida hacia los objetivos de la historia social. Paradójicamente, no nos hemos hecho eco de aquello cercano a nosotros, y a cuya influencia supuestamente deberíamos haber sido más susceptibles, es decir, a lo procedente de Estados Unidos de América. La suya es una historia oral más mecanicista, más utilitaria, más encaminada hacia la creación, preservación y acumulación de archivos testimoniales, $\mathrm{y}$ cuya entrevista «know-how» adquiere una importancia considerable. Es cierto que en un análisis a vista de pájaro podemos observar, en los trabajos llevados a cabo en USA, diversas tendencias que fluctúan entre proyectos sobre relevantes figuras políticas y rescates de experiencias personales en comunidades minoritarias: negros, hispanos, judíos, polacos, etc. En contadas ocasiones la entrevista es un fin por sí misma, sino que, por lo general, forma parte de un 
proyecto más vasto promovido por alguna fundación, biblioteca estatal o archivo universitario

Allan Nevins fue un pionero de la Historia Oral. No solo por trabajar en ella en los primeros años del siglo XX, sino por su propuesta inicial asociada a la necesidad de recuperar a todos los actores sociales y tener en cuenta a los diversos lectores, a todo el espectro de participantes de un determinado proceso histórico.

Esta mirada inclusiva e integral respecto de la Historia que se fue mecanizando a lo largo del siglo XX, se ha ido recuperando y retomando a en las últimas décadas y ha sido determinante para generar posturas que llevan a acciones ciudadanas en países que se han visto impactados por la violencia, las guerras, los gobiernos no democráticos, la censura y la discriminación hacia las libertades básicas establecidas, en 1948, en la Declaración Universal de los Derechos Humanos.

En pleno siglo XXI, la mirada pionera de Allan Nevins imprime su huella y se fortalece en la respuesta ciudadana para dar testimonio de sus historias de vida y su presencia real, aún detrás de la escena y los reflectores mediáticos.

\section{Sustentabilidad, ese difícil objeto del deseo}

En 1987, el informe Brundtland, "Nuestro futuro común", presenta al mundo la definición de desarrollo sustentable como "el desarrollo que cubre las necesidades del presente sin comprometer la capacidad de las futuras generaciones para cubrir las propias"

Gro Harlem Brundtland, presidenta de la comisión de Naciones Unidas, en su presentación ya mencionaba la necesidad de un trabajo conjunto dirigido a proteger el medio ambiente, entendido como el espacio donde se desarrollas las actividades humanas amén de los recursos naturales. No solamente Chernobyl o la hambruna africana sino víctimas de crisis de deudas internas por disminución de ingresos. La necesidad de relacionar al hombre, sus acciones y consecuencias respecto de las distintas dimensiones del desarrollo humano, se reflejan en la frase: "El medio ambiente no existe como esfera separada de las acciones humanas, las ambiciones y demás necesidades" (Brundtland, 1987)

En 1972, quince años antes del pronunciamiento Brundtland, el antecedente que desató la necesidad de que los países se sentaran a la mesa de negociaciones para pensar sobre el futuro del planeta, lo constituye la Conferencia de las Naciones Unidas sobre el Medio Ambiente Humano, en Estocolmo, Suecia, en la cual se enfatiza sobre la urgente necesidad de generar acciones prudentes sobre el uso de nuestro planeta:

A nuestro alrededor vemos multiplicarse las pruebas del daño causado por el hombre en muchas regiones de la tierra, niveles peligrosos de 
contaminación del agua, del aire, de la tierra y de los seres vivos; grandes trastornos del equilibrio ecológico de la biosfera; destrucción y agotamiento de recursos insustituibles y graves deficiencias, nocivas para la salud física, mental y social del hombre, en el medio ambiente por él creado (...) La defensa y el mejoramiento del medio ambiente humano para las generaciones presentes y futuras se ha convertido en meta imperiosa de la humanidad

\section{JUAN LUIS CIFUENTES LEMUS y el ser sustentable}

En los últimos treinta años, hubo otras cumbres por la defensa de la Tierra, como la de Río 92 en las que se continúa reclamando a los líderes políticos la toma de conciencia sobre la necesidad de incorporar a la sustentabilidad en el quehacer cotidiano de cada ser humano así como tomar medidas enérgicas y concretas para proteger el planeta.

Pionero de la sustentabilidad, en 1970, Juan Luis Cifuentes Lemus, escribe Panorama general de la contaminación de las aguas en México (Cifuentes, J.; Rodríguez, R.; Zarur, A.). En el texto, se realiza una revisión de la situación de México, respecto de la contaminación de los océanos, durante el año 1969. Se evalúan, con datos precisos, la afectación que produce la modernidad y la industrialización, así como el crecimiento demográfico, sobre el territorio. Se presentan referencias de distintos estados de la república en los cuales se verifican ya efectos de contaminación.

Se pueden señalar como principales fuentes de contaminación del agua en México, a la industria del petróleo y sus derivados; a las aguas negras; a los desechos de las industrias cervecera, azucarera, alimentaria; a los derivados de la minería, metalurgia; asimismo a los productos farmacéuticos y químicos y a los de las fibras artificiales, la celulosa, los hilados y tejidos y, por último, a los que se desprenden de la agricultura, actividad que cada día presenta un mayor desarrollo en el país.

Frente al conflicto que genera la contaminación de las aguas tanto continentales como marítimas, la investigación remite al trabajo que deben realizar las autoridades para salvaguardar el patrimonio natural mexicano. Por ejemplo, con el fin de proteger la pesca, como efecto de la negación de permisos a las empresas internacionales para acceder a descargar en aguas territoriales mexicanas, se señala que se han producido acciones de reciclado de sobrantes, aunque "se ha observado una renuencia por parte de la mayoría de los industriales para acatar las disposiciones, aduciendo para ello incosteabilidad en la instalación y operación de los sistemas adecuados para el tratamiento de los desechos"

A su vez, y de manera muy precisa, se señala la necesidad de que la comunidad ciudadana forme parte de la tarea de protección frente a las acciones de contaminación producto de la modernidad, por ejemplo, tomar 
conciencia del aprovechamiento de los desechos así como la modalidad de almacenarlos en lugares seguros.

Con base en la presencia internacional en defensa de los sistemas bióticos que durante décadas ha ejercido Juan Luis Cifuentes Lemus, se realizó una entrevista, durante el mes de julio de 2017, en el Centro Universitario de la Costa, Campus Puerto Vallarta, Universidad de Guadalajara, México, institución en la cual realiza actividades académicas al día de hoy. En ella, con los principios de la Historia Oral, da testimonio de su permanente trabajo por la sustentabilidad.

Cifuentes Lemus nace en 1929 en Ciudad de México. Obtuvo el título de Biólogo en 1954 y la maestría en Ciencias en 1972, ambas por la Universidad Nacional Autónoma de México (UNAM). Imparte clases desde 1953 y se mantiene activo en 2017.

Fue secretario (1965-1966 y 1971-1973) y director de la Facultad de Ciencias de la UNAM (1973-1977). En su labor externa a la académica, fue Subdirector de Asuntos Biológicos Pesqueros en la Dirección de Pesca de la Secretaría de Industria; fue representante en México en comisiones como el Comité de Pesca de la FAO (Organización de las Naciones Unidas para la Agricultura y la Alimentación); Director del programa de investigación y fomento pesquero $\mathrm{MEXICO} / \mathrm{FAO}$

La cátedra nacional de biología del Consejo de Universidades Mexicanas lleva el nombre Juan Luis Cifuentes Lemus. Cuenta con 11 doctorados Honoris Causa. Existen 3 especies de seres vivos nominadas científicamente con su apellido.

Con el fin de escuchar su testimonio como informante clave respecto del concepto de sustentabilidad y su desarrollo en las últimas décadas, se presenta un fragmento de la entrevista mencionada:

¿Cuándo fue la primera vez que usted oyó hablar sobre sustentabilidd o qué otro nombre recibía antes?

Mire, desde que estaba yo en primaria hace muchos se hablaba del aprovechamiento racional de los recursos naturales y cuidar el ambiente todavía no se había inventado la palabra medio ambiente que es un pleonasmo, medio o ambiente, pero ya desde que éramos niños de kínder nos hacían hacer contacto con los recursos naturales, los seres vivos a parte de la especie humana y con el ambiente donde se encontraban esos seres vivos (...) Todo esto iba haciendo que usted conociera los seres vivos que usted conociera donde estos seres vivos vivían y yo siempre he dicho que lo se conoce se quiere y lo que se quiere se cuida. Usted mata una araña porque no la conoce y no sabe el beneficio que le va a dar la araña, usted pone algo para espantar a los murciélagos porque no sabe el beneficio que le van a dar los murciélagos y más en la época actual que lo único que domina 
son los dólares o los euros, que es el pensamiento con el que estamos formando a las generaciones. En los libros, ya veíamos el ciclo del agua de la naturaleza, sabíamos que el peor error que está cometiendo la especie humana es acabar con la carpeta verde porque al acabarse con la carpeta verde hace que el agua amiga se convierta en enemiga. Si me permite se lo describo muy rápidamente.

Por supuesto

Cuando está calentando el sol el océano, se va a producir vapor de agua, vienen los vientos y aquí los sentimos mucho dado que nuestro calor es muy húmedo por suerte, y este vapor de agua va subiendo hacia la montaña y al llegar allá arriba el agua se condensa, la nube pesa y viene la lluvia. Si la ladera está sembrada esa agua va a bajar lentamente y va a ser aprovechada por los vegetales que la van a detener, va a formar un medio hídrico abajo en sus raíces, una capa con agua, y la van a aprovechar los animales y la va a aprovechar la especie humana. Una gota de agua pude tardar hasta 10 años en regresar al mar, reciclándose y aprovechada por los seres vivos, entonces el agua es nuestra amiga. Y los ríos la van a traer en caudales normales a llevarla nuevamente al mar y que se recicle, que venga el ciclo del agua, el agua es nuestra amiga. Pero qué pasa con los desarrolladores, que generalmente son gente de otro lado que viene, no le importa acabar con la capa verde y lo más grave, la va a cambiar por cemento entonces esa gota de agua ya no se va a detener ya va a desparecer la capa hídrica con agua y por lo tanto va a ver carencia de agua potable, porque ahí se está filtrando por eso la tenemos potable en manantiales en lagos en ríos, muy buena calidad en los esteros. Entonces para acabar con esto, esa gota de agua en lugar de diez años, a los tres días está y en qué cantidad, en una cantidad grande que hace que los ríos se inunden y como la población humana es muy cómoda, busca vivir pegadita al río, todas las culturas, la cultura que usted me pregunte está dependiendo de un rio en todos lados. Entonces esa agua amiga se va a volver en agua enemiga vienen las inundaciones vienen los ahogados viene la destrucción y se está transformando el agua amiga en agua enemiga. Hablan de desarrollo sustentable, palabrita que ahora no voy a decir, como yo creo que nació esa palabra, si realmente pensáramos en un desarrollo sustentable mantendríamos la carpeta verde y no cambiaríamos a los árboles por esos edificios tan feos que parecen, decía mi padre, cajas de zapatos con hoyos.

¿Me podría dar su definición de patrimonio?

Patrimonio cultural es lo que nos dejaron las culturas prehispánicas por ejemplo, patrimonio de una herencia es lo que me dejaron mis 
papás, patrimonio de este país es su cultura y sus recursos bióticos, todo eso sería el patrimonio que hay que cuidar.

La verdadera riqueza de un país es su cultura y sus recursos bióticos. México ha tenido muchos problemas sociales, económicos, políticos, pero siempre tenemos que hablar de la historia mexicana, desde los jardines botánicos flotantes de Nezahualcóyotl el zoológico y jardín botánico de Moctezuma hasta la cultura que todavía se sigue produciendo en México, en todos los estados usted encuentra una cultura diferente muy rica, basta ver a los mayas, los nahuas, y los recursos bióticos, insisto estamos entre los 5 países mega diversos que somos México, Colombia, Brasil Indonesia y Australia pero si se hiciera más investigación, que tenemos, podríamos ser el 2do país en biodiversidad.

México, lo podemos presumir, fue uno de los países, con las culturas prehispánicas que ya se preocupaba por los recursos naturales. Nezahualcóyotl en 1430 funda el bosque de Chapultepec llevando ahuehuetes y llevando faunas con la idea de que se necesitaba un pulmón, ahora vaya usted a Santa Fe en Ciudad de México y no ve un árbol y ve edificios y edificios, se siente para los que vivimos en un ambiente un poco más tranquilo, llegamos a Ciudad de México nos lloran los ojos nos sentimos mal por la cantidad de contaminación, no hay árboles. Nezahualcóyotl, rey de Texcoco, estableció la primera veda para los bosques, pero no para no cortarlos sino para cortarlos racionalmente, estamos hablando de 1430 y pena de muerte a aquel que matara una animal en un área protegida, se ve muy rudo pero había que meter orden. Hizo los jardines flotantes en Texcoco, ya cuando llegaron los españoles encontraron en el palacio de Moctezuma lo que hoy llamamos un zoológico y un jardín botánico, muchos años antes de que estuvieran en Europa. Entonces, había un concepto, conserva los seres vivos para poderlos aprovechar y cuidar racionalmente $(. .$.

Tuve la suerte de organizar la investigación pesquera en este país y me tocó la suerte de echar a andar el programa nacional de la protección de la tortuga marina de las 11 especies y subespecies, si nada más se habla de especies son 8 , pero si se habla de especies y subespecies son 11, y a México llegan 5 al golfo y 5 al Pacífico, solo la kikila llega a Australia. Entonces hicimos la protección de la tortuga. Todas las especies tenemos una curva de crecimiento poblacional y una curva de mortandad, si usted acentúa la curva de mortandad la especie desaparece, pero si la curva de crecimiento poblacional es baja a usted le queda o desparecerla más rápido o hacerla durar más tiempo. Toda tortuga y el cocodrilo como los 
últimos reptiles gigantes, tiene una curva de crecimiento más lenta cuando la explotamos, cuando la dejamos de explotar, ya la explotan algunos que se roban huevos de tortuga etcétera, entonces hemos logrado recuperar algunas especies no para volverlas a explotar, hay otras especies que usted puede explotar porque su curva poblacional es muy grande, una ostiona le da 10 millones de huevecillos, entonces no se van a acabar los ostiones, van a estar tirados de la risa y van a decir esa especie que decía que pensaba, se autodestruyó y el ostión va a estar tranquilo. Esto hay que entenderlo, eso es lo que es el aprovechamiento racional, saber la biología de la especie, conocer su curva de crecimiento de crecimiento poblacional su curva de mortandad natural y no agregar más mortandad por aprovechamiento sino agregar la que la especie aguanta.

En el año 66, todavía estamos hablando de aprovechamiento racional...

México está entre los cinco países megadiversos que son México, Colombia, Brasil, Indonesia y Australia. Yo estoy seguro que si gastáramos más en que estos biólogos que estamos formando conocieran más qué especies, tenemos, sino el primero por lo menos el segundo. Brasil es muy grandote tiene mucha agua pero es plano y ¿cómo es México? con una topografía maravillosa, con una cantidad de ecosistemas...y ¿qué estamos haciendo aquí? Acabando con la montaña. Yo creo que por mi edad no lo voy a ver cuando vengan aquí en Vallarta, inundaciones como las que tienen en Veracruz, Tabasco, por cambiar esa vegetación en la montaña por cemento, por más que me digan, no vamos a hacer un desarrollo sustentable. Si el desarrollo sustentable lo basan en destrucción, no hay nada sustentable.

Más o menos ya por los finales de los 60 empieza la FAO a preocuparse por el aprovechamiento racional de los recursos, en Naciones Unidas empieza a dominar un pensamiento que nace con las delegaciones de pesca de Argentina, Chile y Perú. Perú en ese momento era un país número uno en producción pesquera arriba de Japón, por la anchoveta, porque la anchoveta en la corriente de Humboldt o corriente de Perú, se reproducía, hasta que aparece un cambio en el comportamiento oceánico, viene el fenómeno del niño y se va para abajo y claro, Perú como era mono pesquero tiene grandes problemas. Viene este cambio en la circulación oceánica, esto que le llaman cambio climático y todo el escándalo que hacen, ha existido desde que se formó la esfera que llamamos tierra, claro, no son para pasado mañana son cambios largos, claro, en algunas zonas la especie humana los está acelerando por cuestiones de sacar más dinero, ¿es lo 
que ahora les interesa, no?. Entonces empieza a preocupar esto y se hace una primera reunión mundial para la contaminación de los océanos, se realiza en Londres en 1970 (...)

Como ve, empieza a nivel mundial la preocupación y se realiza en Estocolmo en 1972 la primera reunión sobre medio ambiente y ahí es donde se empieza a hablar de que hay que aprovechar los recursos tratando de no acabárnoslos y de no acabarnos con el ambiente de donde vienen los recursos. Se acababa de fundar el Consejo Nacional de Ciencia y Tecnología, CONACYT, estamos hablando, con el Pdte. Echeverría y en la Secretaría de Salud se establece en México la primera Subsecretaría de Ecología; entonces hay una preocupación. Se hace la reunión allá en Estocolmo, salen algunas reglas, hay preocupación, aquí en México se empiezan a tomar medidas para construir sin lesionar a los recursos del ambiente y nace Cancún. Entonces en Cancún se hace una comisión de CONACYT, tuve la suerte de que también me invitaran, y recomendamos que los hoteles los construyeran atrás de los humedales no a la orilla de la playa porque dijimos, es zona de ciclones y los humedales van a detener la arena, los humedales van a estabilizarte el litoral los humedales...todo lo que quieras. Treinta años después les pega el ciclón y nos da la razón, adiós playas de Cancún adiós arena finita, ¿qué tienen que estar haciendo ahora? Inyectando arena que traen de Belice para tener playas en Cancún y han tenido suerte que NO les hayan pegado otros ciclones porque si no hubieran ido a cimientos de hoteles $(. .$.

Para mí la equivocación más grande de la especie humana que, subrayo, se va a auto destruir, va a acabar con la gente, la vida en el mundo es una presunción, a menos que tiren 40 bombazos atómicos, el error es que todo lo que están pensando es en dinero, en la economía usted lo ve, gente con 10 departamentos en todo el mundo, usted ve aquí en Puerto Vallarta gente muy rica y va a los lugares y ve gente muy pobre (...) Ahora, la buena noticia es que en la protección de la tortuga de la playa de la escobilla en Oaxaca nos están llegando arribazones de la tortuga golfina de 300 mil tortugas pero hay un problema llegan una noche $300 \mathrm{y}$ otra noche llegan $10 \mathrm{y}$ les tapan los nidos a las anteriores. Ahí tenemos otro reto.

¿Y eso es porque cada vez tienen menos lugar?

Por lugar sí, dijo usted la palabra clave ella viene a hacer su nido y no está viendo si ahí hay un nido de antes.

La situación es semejante a la que nos pasó aquí en Puerto Vallarta que se quedaron sin espacio, pues ¿dónde pueden anidar? 
Eso es lo que creo, subrayo, que qué bueno que hubiera un desarrollo sustentable, pero realmente ¿sustentable? Pero para los recursos vivos que es lo más importante. La verdadera riqueza de un país es la cultura y los recursos bióticos, esa es la verdadera riqueza de un país, por eso México es tan rico porque....hay pensamientos que dicen: hemos tenido problemas económicos sociales pero nunca culturales y los recursos bióticos yo creo que si los conociéramos y los estuviéramos aprovechando racionalmente este país...

Es que eso es la sustentabilidad: darle calidad de vida a la gente

Si me dice eso, creo en la sustentabilidad, pero creo que no es lo que están haciendo porque darles 10 millones de pesos para que hagan un programita para ellos, los 10 se los van a clavar se les van a ir en muchas cosas pero dígame cuantas gentes cuantas tortas van a producir esos 10 millones de pesos. No, lo que usted me dice es precioso si el desarrollo sustentable es darle calidad a la especie humana estoy de acuerdo, pero vamos a decir a que le llamamos calidad. A que tenga yo un penthouse en un edificio o a que tenga yo que mi familia coma...Los tres derechos para mí de la especie humana son la alimentación, salud y educación, Si usted está alimentado va a tener salud y al tener los dos va a tener educación que le va a permitir que consiga su alimento y consiga su salud.

El presidente mexicano Lázaro Cárdenas, durante su presidencia de 1936 a 1940, también hizo algo con los bosques

Cuando estaba Lázaro Cárdenas yo era niño yo tenía 6 años cuando entró y 10 cuando salió pero Lázaro Cárdenas sí se preocupó también por cosas de los bosques y Lázaro Cárdenas forma el ejido con la idea de un aprovechamiento de grupos de mexicanos que formaran su ejido para trabajar en conjunto y ganar en conjunto y fue una de las cooperativas pesqueras, la cooperativa de la asociación pesquera también con lo mismo que se unieran un grupo de pescadores formaran su cooperativa trabajaran en conjunto y ganaran en conjunto Eso sería una forma de sutentabilidad; y respecto de la gente que habita el país, respecto de los mexicanos ¿en qué sentido el mexicano, los hombres y mujeres de este país pueden tener presencia en el patrimonio y en la sustentabilidad?

Mi padre no era mexicano era nicaragüense pero él se hizo más mexicano que los mexicanos, es decir regresando lo que el país le está dando y haciendo un esfuerzo para lograr que el país se desarrolle y vivan mejor lo que aquí tuvieron la suerte de nacer y que el colaboró mucho porque era médico que esto sucediera entonces así se integró a la cosa de patrimonio, pero además el sabia más historia de México y conocía más toda la parte cultural de México que mucho 
mexicanos , como él viajaba tanto podía conoce la cultura maya la zapoteca la mixteca, etc, usted va encontrando en México un mapa cultural muy interesante donde se ve la cultura que tiene los de Baja California es muy diferente a la cultura que tienen los de Quintana Roo y de Yucatán totalmente distinto, entonces toda esta cultura es lo que hay que dar a conocer a la gente para que la conozca la quiera y la cuide, igual, si usted le enseña los bonitos recursos de seres vivos de plantas y animales que hay en toda la república y en todas sus costas la gente la conoce y al conocerla la quiere y al quererla la va a cuidar.

Nada más le voy a pedir que me diga si permite que su testimonio, tal como ha sido dicho, sea publicado:

Con todo gusto tiene usted toda mi autorización. Esto no es de Cifuentes; esto es dinero de este país que me ha dado y todo lo que yo publico, mis conferencias y todo, a todo el mundo le digo que tienen toda mi autorización de usarlo como quieran

\section{Sustentabilidad e Historia Oral: conceptos culturales}

Morin (2011) señala que, al sumar al concepto "desarrollo" el adjetivo "sustentable" se le da un claro componente ético que señala una toma de conciencia frente a la desmesura y que se relaciona con cuestiones de protección ambiental la cual, luego, son manejados por intereses particulares que desdicen el propio objetivo.

En consecuencia, la toma de conciencia de la crisis ha generado el agregado "sustentable" a la noción de desarrollo pero no es suficiente debido a la globalización y la visión y aplicación misma de "desarrollo".

Los conceptos de crecimiento y desarrollo, como caras de una misma moneda, han sufrido una transición desde la misma idea de que el crecimiento económico llevaba al desarrollo hasta pensar si existe realmente un desarrollo que no sea sustentable.

Mirada coincidente al planteamiento de Morin es la que realiza la Unión Europea (2009) quien plantea superar el concepto de prosperidad y desarrollo como crecimiento económico y crear las condiciones de bienestar frente a las coyunturas derivadas de los procesos económicos y políticos de las últimas décadas. Se suma a la mirada sobre el medio ambiente ya que sostiene que el planeta requiere de todos los recursos vivos: "La Unión Europea no necesita una estrategia de competitividad sino una estrategia de prosperidad sostenible" (pág. 3)

Los tres pilares que engloban al desarrollo sustentable son el crecimiento económico, la inclusión social y el equilibrio medioambiental. En 2010, la cultura se suma a ellos, vista como elemento a desarrollar en las políticas públicas de gobierno así como en la gestión de sectores públicos y privados 
relacionados con el patrimonio, el turismo o el arte, tal como lo afirma el documento "Ciudades y Gobiernos Locales Unidos" -CGLU-, avalado por las Naciones Unidas.

Al tiempo que tenemos la obligación de promover la continuidad de las culturas locales indígenas, cada día, en ciudades de todo el mundo, antiguas tradiciones convergen con nuevas formas de creatividad, contribuyendo así a la conservación de la identidad y diversidad. El diálogo intercultural es uno de los mayores desafíos de la humanidad, mientras la creatividad es valorada como un recurso inagotable para la sociedad y la economía. (CGLU, 2010)

En este punto, al hablar de identidad, diálogo intercultural y diversidad, la cultura como patrimonio, roza a la Historia Oral que durante el siglo XX se ha ocupado de recuperar aquellos testimonios de personas que, por motivos de imposibilidad de diálogo o por opiniones divergentes respecto del discurso dominante, fueron silenciadas negándoseles su propia identidad al querer desaparecerlos en crematorios y tumbas NN. Estas acciones constituyeron una pérdida de patrimonio cultural que afectó a millones de personas alrededor del planeta.

Para ambos conceptos, la década del 70 fue el inicio para ir pasando de las generalizaciones a las especificaciones y concreciones: en el caso del desarrollo sustentable, desde la mención por los organismos internacionales de una mirada no solo de medio ambiente natural sino humano, y cubrirse dentro de las cuestiones de ecología, hasta la toma de conciencia de la necesidad de posicionar al ser humano en la misma medida que la naturaleza; en cuanto a la historia oral, desde su definición metodológica y la diferenciación con otras áreas de las disciplinas científicas, hasta la aplicación para recuperar voces y testimonios de situaciones de violencia hacia las personas.

\section{Conclusion:}

La Historia Oral es, por definición, una metodología; sin embargo durante el Siglo XX ha resultado en la implicación de una postura de resistencia y lucha para dar a conocer episodios de crueldad y violencia entre los hombres, de tortura y violación a los derechos humanos. Ha adquirido nuevas connotaciones al puntualizar y darle valor de documento histórico a los testimonios, las cuales son, en sí mismos, origen y destino de la labor.

La sustentabilidad y la Historia Oral forman parte de apropiaciones ciudadanas las cuales articulan, en caso de la primera, una mirada hacia el futuro $\mathrm{y}$, en cuanto a la segunda, la salvaguarda de la memoria colectiva en contextos clave de conflicto social. En consecuencia, son conceptos que pueden ser considerados herramientas para el cambio social. Desde el presente se recupera patrimonio que es herencia del pasado y se fortalecen 
lazos para sostener construcciones de un futuro con el mayor bienestar para cada uno de los seres humanos.

Por ello, trabajar en Historia Oral es una elección, un recorte de todas las posibilidades en juego; es una decisión política, ética y ciudadana. Es una metodología, pero es aplicada por un proceso selectivo que la ubica en un plano de toma de conciencia y compromiso para generar archivos vivos que se podrán oír en el futuro.

Historia Oral y Sustentabilidad son dos conceptos que adquieren fuerza expresiva y participativa en la Era Planetaria. Su complejidad se desentraña a partir de la toma de conciencia y valoración con la posterior acción humana participativa, ciudadana y responsablemente sustentable en cuanto a la protección de su patrimonio debido al compromiso que han ido adquiriendo en defensa de su futuro y de las posteriores generaciones.

¿Por qué pensar estos conceptos con una mirada conjunta? Debido a que constantemente ejercen nuevos límites de posicionamiento sobre sus alcances; asimismo, tienden al compromiso y a la toma de conciencia respecto del statu quo dominante y con línea de pensamiento unívoca y las acciones para revertirla. En definitiva, ¿Por qué pensarlos en conjunto? Porque ambos buscan salvaguardar el patrimonio natural y cultural del pasado y del presente para un futuro terrestre posible.

¿Cuál es el objetivo de la sustentabilidad? Proteger a los seres vivos, inclusive, de sí mismos y velar por el futuro; ¿y qué persigue la Historia Oral? Ser un recurso científico asociado al compromiso que fortalece a las Ciencias Sociales y a la gestión de ciudadanos cuyas voces son recuperadas como parte integral de quienes conforman los procesos históricos.

Tanto Allan Nevins con la Historia Oral como Juan Luis Cifuentes Lemus con el aprovechamiento racional de los recursos -la sustentabilidad-, dirigen sus reflexiones y accionar tomando en cuenta la compleja realidad del entrecruce de las dimensiones humanas, en la Era Planetaria descrita por Edgar Morin.

La responsabilidad es imprescindible a nivel ciudadano y debe ser, también, traducida en medidas de acción política y reformas legislativas públicas y privadas por parte de los gobiernos, con una proyección a mediano y largo plazo, que exceda los cambios de coyuntura y partidos políticos en el poder.

Quienes niegan la complejidad del mundo en que vivimos, sostienen una mirada unívoca que marca un determinado camino, sin desvíos ni alternativas; sin embargo, pertenecer a una sociedad, ser un ciudadano del siglo XXI nos presenta esta otra mirada: la sustentabilidad y la Historia Oral sirven para dejar huella. La pregunta es ¿Quién marcará la pisada que firme la lectura de nuestro pasado y decida sobre nuestro futuro?

Este es, tal vez, el mayor desafío al que nos enfrentamos 


\section{References:}

1. American Heritage (1954) "The Oral History Project of Columbia University". En American Heritage, december, volumen 6, issue 1.

2. Brundtland, G. (1987) Informe de la Comisión Mundial sobre el Medio Ambiente y el Desarrollo. Nota del Secretariado General. https://es.scribd.com/doc/105305734/ONU-Informe-Brundtland-Ago1987-Informe-de-la-Comision-Mundial-sobre-Medio-Ambiente-yDesarrollo

3. Ciudades y gobiernos locales Unidos -CGLU- (2010) "La cultura es el cuarto pilar del desarrollo sostenible". En http://www.agenda21culture.net/sites/default/files/files/documents/es/ zz_cultura4pilards_esp.pdf

4. Comisión de las Comunidades Europeas (2009) "Consulta sobre la futura estrategia UE2020”. En http://ec.europa.eu/eu2020/pdf/eu2020_es.pdf

5. Hill, E. (1974) The reminiscences of Allan Nevins. Oral History Research Office. Columbia University

6. Meyer, E (1980) "Oral History in Mexico and Latin America." En International Journal of oral history, febrero, pág. 79-81.

7. Meyer, E. (1989) "Recuperando, recordando, denunciando, custodiando la memoria del pasado puesto al día. Historia oral en Latinoamérica y el Caribe.” En Historia y Fuente Oral. 5, pág. 139144.

8. Morin, E. (2007) (2011) ¿Hacia dónde va el mundo? España: Paidós

9. Morin, E. (2011) La vía para el futuro de la humanidad. España: Paidós

10. Organización de las Naciones Unidas (1972) "Conferencia sobre el medio ambiente humano. Declaración de Estocolmo". En http://www.ordenjuridico.gob.mx/TratInt/Derechos\%20Humanos/IN ST\%2005.pdf

11. Organización de las Naciones Unidas (2015) "Los objetivos del Desarrollo Sustentable". En http://www.un.org/sustainabledevelopment/es/cities/ 